\title{
Recent Advances in Electron Crystallography
}

\author{
Jeong Min Chung ${ }^{\dagger}$, Sangmin Lee ${ }^{\dagger}$, Hyun Suk Jung*
}

Department of Biochemistry, College of Natural Sciences, Kangwon National University, Chuncheon 24341, Korea

\author{
${ }^{\dagger}$ These authors contributed equally \\ to this work. \\ *Correspondence to: \\ Jung $\mathrm{HS}$, \\ Tel: $+82-33-250-8513$ \\ Fax: +82-33-259-9363 \\ E-mail: hsjung@kangwon.ac.kr
}

Received August 7, 2017

Revised September 6, 2017

Accepted September 8, 2017

\begin{abstract}
Electron crystallography has been used as the one of powerful tool for studying the structure of biological macromolecules at high resolution which is sufficient to provide details of intramolecular and intermolecular interactions at near-atomic level. Previously it commonly uses two-dimensional crystals that are periodic arrangement of biological molecules, however recent studies reported a novel technical approach to electron crystallography of three-dimensional crystals, called micro electron-diffraction (MicroED) which involves placing the irregular and small sized protein crystals in a transmission electron microscope to determine the atomic structure. In here, we review the advances in electron crystallography techniques with several recent studies. Furthermore, we discuss the future direction of this structural approach.
\end{abstract}

Key Words: Electron crystallography, Protein structure, Transmission electron microscopy, Micro-electron diffraction, Structural biology

\section{INTRODUCTION}

The ultimate goal of structural biology is to understand the protein function and its physiological mechanisms by determining the three-dimensional (3D) structure. Several techniques have been used for the purpose, including X-ray crystallography, nuclear magnetic resonance (NMR), and electron microscopy (EM). X-ray crystallography is the most successful technique for the structural study of many proteins (Berman et al., 2000). In a traditional X-ray crystallography, $\mathrm{X}$-ray beam is directed towards protein crystal, resulting in the scattering portions of X-ray photons to form a diffraction pattern. During the process, the crystal is rotated at small angles and other diffraction patterns are recorded. Eventually, after repeated iterations, the structure of the protein can be reconstructed from the accumulated diffraction patterns (Shi et al., 2013). Although, there is a great development in X-ray crystallography, it still remains a bottleneck for protein structure determination. The crystal used in X-ray crystallography must be large well-ordered. However, some proteins such as membrane proteins and protein complexes, may never yield the large well-ordered crystals and it takes significant time and resources to optimize the initial small crystals found during the screening process (Bill et al., 2011). Since early 1940s, electron diffraction has been used to solve the crystallographic problems (Bendersky \& Gayle, 2001). The basic principle of electron crystallography is similar to X-ray crystallography in a concept that protein crystals scatters electron beam to produce a diffraction pattern. The crystals that are used in the electron crystallography are needed to be thinner than X-ray crystal as the interacting power of electron is much stronger than that of X-ray photons (Henderson \& Unwin, 1975; Kimura et al., 1997; Kuhlbrandt et al., 1994). Over the past decades, the electron crystallography has been successfully used to determine the structure of several difficult proteins with two-dimensional crystals (2D electron crystallography) (Wisedchaisri et al., 2011). However, this technique is normally only possible to produce one diffraction pattern from each crystal as electrons have very high energy which causes a large amount of radiation damage to the sample crystals, resulting in the loss of structural information (Glaeser, 1971). To overcome this, the electron diffraction patterns that are produced from hundreds of individual crystals are merged to generate a single data set. Not surprisingly, several studies have conducted the electron crystallography using 3D protein crystals over

(a) This is an open-access article distributed under the terms of the Creative Commons Attribution Non-Commercial License (http://creativecommons.org/licenses/by-nc/4.0) which permits unrestricted noncommercial use, distribution, and reproduction in any medium, provided the original work is properly cited.

Copyrights @ 2017 by Korean Society of Microscopy 
the past decades, but it has until recently failed to determine the atomic structure. However, A recent study reported a novel technical approach to electron crystallography, called micro electron-diffraction (MicroED) providing a striking feasibility to determine high-resolution protein structures by using electron crystallography of 3D protein crystals (Shi et al., 2013). In this paper, we review the technical advances in electron crystallography of $2 \mathrm{D}$ and $3 \mathrm{D}$ crystals with several recent studies (Table 1 ).

\section{D ELECTRON CRYSTALLOGRAPHY}

2D electron crystallography records electron micrographs of 2D crystals. Such 2D crystals are periodic arrangement of molecules (e.g., proteins). This allows determination of high-resolution structural details as a single micrograph of $2 \mathrm{D}$ crystals of large numbers of identical subunits arranged in same orientation. The basic concept of electron crystallography is similar to X-ray crystallography. Henderson and Unwin (1975) were the first to use electron crystallography in their structural analysis of the integral membrane protein bacteriorhodopsin (Henderson, 1975). They showed that EM could be used for the molecular structure determination at subnanometer resolution. In 1990 a near atomic resolution structural analysis showed the potential of electron crystallography as a competitive alternative to X-ray crystallography in the determination of membrane protein structure (Henderson et al., 1990). Electron crystallography was initially used to determine the membrane protein structure by reconstituting the protein into 2D crystals with lipid (Pope \& Unger, 2012; Raunser \& Walz, 2009). Recently, electron crystallography has been applied to the structural study of soluble proteins that has been dominated by X-ray crystallography and NMR spectroscopy (Ellis \& Hebert, 2001). In applying electron crystallography the study of soluble proteins, the formation of large, coherent and stable $2 \mathrm{D}$ protein arrays and reproducible transfer of the arrays to the EM grid are required. Several soluble proteins have been investigated using electron crystallography including 2D crystals of viral capsid proteins (Ganser-Pornillos et al., 2007; Purdy et al., 2008). Structural information on $2 \mathrm{D}$ protein crystals can be obtained by recording on film or using charge-coupled device cameras real-space images or electron diffraction patterns. The spots of the diffraction patterns that can be evaluated to give the amplitudes of the protein structure. However, if the $2 \mathrm{D}$ crystal is poorly ordered, only low-resolution diffraction orders can be obtained which are unsuitable for the structural determination. Fourier transformation of real-space images of $2 \mathrm{D}$ crystals can give access to the amplitude and phases of the protein structure. If the $2 \mathrm{D}$ crystal has moderate defects, the crystal distortion can be computationally corrected before the mathematical calculation of the Fourier transformation in a process called "unbending" (Schenk et al., 2010). The unbending process improves the number and quality of highresolution spots in the calculated Fourier transformations of images and this gives the access to higher resolution information (Schenk et al., 2010). The MRC suite of programs implement all of the computer data processing required for electron crystallography. The use of image processing programs used to require significant background knowledge and experience and they were also cumbersome. However, a recently developed user-friendly graphical interface with the MRC programs, called the $2 \mathrm{dx}$ software package, makes easier and accelerates the computer image processing for electron crystallography (Gipson et al., 2007). In order to generate 3D model from 2D crystals, the specimen can be tilted in the EM to obtain the sample at various angles. Untilted images are used as reference to provide a common phase origin for the tilted data set. The individual image datasets can then be merged into one big dataset via several steps: symmetrization, scaling, merging, tilt geometry refinement, lattice line fitting and discretization.

Table 1. Recently reported reference lists for high-resolution structure of proteins using two-dimensional (2D) and three-dimensional (3D) electron crystallography

\begin{tabular}{|c|c|c|c|c|}
\hline Protein (M.W) & Resolution $(\AA)$ & Instrumentation & $2 \mathrm{D}$ or $3 \mathrm{D}$ crystal & Reference \\
\hline Tau VQIVYK peptide (0.000747 MDa) & 1.1 & TF20 (FEI) & $3 \mathrm{D}$ crystal & de la Cruz et al., 2017 \\
\hline$\alpha$-Synuclein residues $69-78$ (0.001 MDa) & 1.4 & TF20 (FEI) & $3 \mathrm{D}$ crystal & Rodriguez et al., 2015 \\
\hline Proteinase K (28.9 kDa) & 1.6 & TF20 (FEI) & $3 \mathrm{D}$ crystal & de la Cruz et al., 2017 \\
\hline Lysozyme (0.0143 MDa) & 2.5 & TF20 (FEI) & $3 \mathrm{D}$ crystal & Nannenga et al., 2014b \\
\hline Catalase (0.24 MDa) & 3.2 & TF20 (FEI) & $3 \mathrm{D}$ crystal & Nannenga et al., 2014a \\
\hline Aquaporin-0 (0.12 MDa) & 1.9 & JEM3200 (JEOL) & $2 \mathrm{D}$ crystal & Gonen et al., 2005 \\
\hline Rhodopsin (0.0390 MDa) & 5.5 & TF30 (FEI) & $2 \mathrm{D}$ crystal & Ruprecht et al., 2004 \\
\hline Connexin26 (0.3 MDa) & 6.0 & JEM3000 (JEOL) & $2 \mathrm{D}$ crystal & Oshima et al., 2011 \\
\hline Citrate/sodium symporter (0.095 MDa) & 6.0 & CM200 (FEI) & $2 \mathrm{D}$ crystal & Kebbel et al., 2013 \\
\hline Sodium proton antiporter (0.046 MDa) & 6.0 & JEM3000 (JEOL) & $2 \mathrm{D}$ crystal & Paulino et al., 2014 \\
\hline
\end{tabular}




\section{D ELECTRON CRYSTALLOGRAPHY}

In a conventional X-ray crystallography, the size limitation of a crystal for adequate diffraction data with a regular synchrotron is $>50 \mathrm{~mm}$ in length. In the case of difficult objects, such as large protein complexes, time and resources are extensively wasted to yield the well diffracting large crystals. Thus, it is highly required for the collection of high-quality diffraction data from small-sized crystal (approximately $<10 \mathrm{~mm}^{3}$ ). Recently developed X-ray free electron lasers (X-FELs) can afford to the structural determination of such crystals (Boutet et al., 2012). This is an emerging method for the structural determination of 3D crystals which ranges from a few micrometers to hundred nanometers in size (Boutet et al., 2012). In the experiment of X-FELs, millions of small sized crystals are continuously passed through the X-ray beam, resulting in the formation of thousands of individual diffraction "snap shots" which will eventually be merged to reconstruct high-quality 3D structure. However, more recent studies suggested that the small crystals are still suffered from the radiation damage (Nass et al., 2015). Although the novel X-ray crystallography technique, X-FELs, is the most promising approach in nanocrystallography, it has several limiting factors including, large amount of sample requirement and high cost.

The most recently developed method, called MicroED, is the electron crystallography technique which allows the collection of high quality electron diffraction patterns using extremely small-sized 3D crystals, ranging of 0.1 to $0.4 \mathrm{~mm}$ thick (Shi et al., 2013). In 2D electron crystallography, electron dose that is required for the adequate diffraction data is relatively high and due to the reason, it can only produce a single diffraction pattern per a crystal. Thus, diffraction patterns from large number of individual crystals must be merged to reconstruct the 3D structure. Like 2D crystallography, a traditional approach of 3D electron crystallography only collects a single electron diffraction data per a crystal. Because of the reason, indexing single diffraction patterns was extremely difficult due to the lack of sufficient information in a single diffraction pattern. With developments in hardware and software, a recent study overcome the difficulties in indexing and merging process by collecting a complete diffraction data set from a single nanocrystal under low electron dose condition $\left(\sim 10 \mathrm{e}^{-} / \AA\right)$ (Shi et al., 2013). In the study, the diffraction dataset of a single crystal were recorded as a series of snap shot by rotating the crystal $\left(0.1 \sim 1^{\circ}\right)$. However, the rotation must be paused during the exposure which causes the drifting issues. More recent study used the improved data collection protocol, called the continuous-rotation mode for MicroED, which oscillates the crystal during the exposure that allows to measure more accurate intensities due to finely sampled reciprocal space (Nannenga et al., 2014b). Although, some modifications are still required for the method, several highresolution structures have been reported (Nannenga et al., 2014a, 2014b; Yonekura et al., 2015).

\section{CONCLUSIONS}

An electron crystallography is not a novel EM technique and its concept has been modified and improved from 2D to 3D crystallography. The fundamental bottlenecks appearing on 3D crystallography have been solved by developments of hardware (improvements in detector and aberration corrector) and software (powerful software algorithms). Even though, several studies have been successfully reported high-resolution structures using 3D electron crystallography, it still has some factors required to be improved such as experimental phasing as phase of electron diffractions cannot be measured. The phase information is crucial factor for crystallography and it requires an accurately integrated diffraction intensities and improved electron scattering tables for atomic model mapping (Scherer et al., 2014; Wisedchaisri \& Gonen, 2011). Several strategies have been conducted to obtain the phase information, including heavy metal isomorphous replacement and changing wavelength of an electron beam, but it has still not been clearly resolved yet. Although, further studies are highly needed to resolve the phasing problem, 3D electron crystallography is highly promising and complementary tool for structural biology.

\section{CONFLICT OF INTEREST}

No potential conflict of interest relevant to this article was reported.

\section{ACKNOWLEDGMENTS}

This research was supported by Basic Science Research Programs through the National Research Foundation of Korea funded by the Ministry of Science, ICT \& Future Planning (NRF-2015R1C1A1A01053611 to H. S Jung and NRF-2017R1A6A3A11035320 to S. Lee), Global Frontier Research Grant (NRF-M1AXA002-2011-0031424 to H. S Jung), Next-Generation BioGreen Program (SSAC, PJ011891 to H. S Jung), and 2016 Research Grant from Kangwon National University (No. 520160527). 


\section{REFERENCES}

Bendersky L A and Gayle F W (2001) Electron diffraction using transmission electron microscopy. J. Res. Natl. Inst. Stand. Technol. 106, 997-1012.

Berman H M, Westbrook J, Feng Z, Gilliland G, Bhat T N, Weissig H, Shindyalov I N, and Bourne P E (2000) The protein data bank. Nucleic. Acids. Res. 28, 235-242.

Bill R M, Henderson P J, Iwata S, Kunji E R, Michel H, Neutze R, Newstead S, Poolman B, Tate C G, and Vogel H (2011) Overcoming barriers to membrane protein structure determination. Nat. Biotechnol. 29, 335-340.

Boutet S, Lomb L, Williams G J, Barends T R, Aquila A, Doak R B, Weierstall U, DePonte D P, Steinbrener J, Shoeman R L, Messerschmidt M, Barty A, White T A, Kassemeyer S, Kirian R A, Seibert M M, Montanez P A, Kenney C, Herbst R, Hart P, Pines J, Haller G, Gruner S M, Philipp H T, Tate M W, Hromalik M, Koerner L J, van Bakel N, Morse J, Ghonsalves W, Arnlund D, Bogan M J, Caleman C, Fromme R, Hampton C Y, Hunter M S, Johansson L C, Katona G, Kupitz C, Liang M, Martin A V, Nass K, Redecke L, Stellato F, Timneanu N, Wang D, Zatsepin N A, Schafer D, Defever J, Neutze R, Fromme P, Spence J C, Chapman H N, and Schlichting I (2012) Highresolution protein structure determination by serial femtosecond crystallography. Science 337, 362-364.

de la Cruz M J, Hattne J, Shi D, Seidler P, Rodriguez J, Reyes F E, Sawaya M R, Cascio D, Weiss S C, Kim S K, Hinck C S, Hinck A P, Calero G, Eisenberg D, and Gonen T (2017) Atomic-resolution structures from fragmented protein crystals with the cryoEM method MicroED. Nat. Methods 14, 399-402.

Ellis M J and Hebert H (2001) Structure analysis of soluble proteins using electron crystallography. Micron 32, 541-550.

Ganser-Pornillos B K, Cheng A, and Yeager M (2007) Structure of fulllength HIV-1 CA: a model for the mature capsid lattice. Cell 131, 7079.

Gipson B, Zeng X, and Stahlberg H (2007) 2dx_merge: data management and merging for 2D crystal images. J. Struct. Biol. 160, 375-384.

Glaeser R M (1971) Limitations to significant information in biological electron microscopy as a result of radiation damage. J. Ultrastruct. Res. 36, 466-482.

Gonen T, Cheng Y, Sliz P, Hiroaki Y, Fujiyoshi Y, Harrison S C, and Walz T (2005) Lipid-protein interactions in double-layered two-dimensional AQPO crystals. Nature $\mathbf{4 3 8}, 633-638$.

Henderson R (1975) The structure of the purple membrane from Halobacterium hallobium: analysis of the X-ray diffraction pattern. $J$. Mol. Biol. 93, 123-138.

Henderson R, Baldwin J M, Ceska T A, Zemlin F, Beckmann E, and Downing K H (1990) Model for the structure of bacteriorhodopsin based on high-resolution electron cryo-microscopy. J. Mol. Biol. 213, 899-929.

Henderson R and Unwin P N (1975) Three-dimensional model of purple membrane obtained by electron microscopy. Nature 257, 28-32.

Kebbel F, Kurz M, Arheit M, Grutter M G, and Stahlberg H (2013) Structure and substrate-induced conformational changes of the secondary citrate/sodium symporter CitS revealed by electron crystallography. Structure 21, 1243-1250.

Kimura Y, Vassylyev D G, Miyazawa A, Kidera A, Matsushima M, Mitsuoka K, Murata K, Hirai T, and Fujiyoshi Y (1997) Surface of bacteriorhodopsin revealed by high-resolution electron crystallography. Nature 389, 206-211.

Kuhlbrandt W, Wang D N, and Fujiyoshi Y (1994) Atomic model of plant light-harvesting complex by electron crystallography. Nature $\mathbf{3 6 7}$, 614-621.

Nannenga B L, Shi D, Hattne J, Reyes F E, and Gonen T (2014a) Structure of catalase determined by MicroED. Elife $\mathbf{3}, \mathrm{e} 03600$.

Nannenga B L, Shi D, Leslie A G W, and Gonen T (2014b) High-resolution structure determination by continuous-rotation data collection in MicroED. Nat. Methods 11, 927-930.

Nass K, Foucar L, Barends T R, Hartmann E, Botha S, Shoeman R L, Doak R B, Alonso-Mori R, Aquila A, Bajt S, Barty A, Bean R, Beyerlein K R, Bublitz M, Drachmann N, Gregersen J, Jonsson H O, Kabsch W, Kassemeyer S, Koglin J E, Krumrey M, Mattle D, Messerschmidt M, Nissen P, Reinhard L, Sitsel O, Sokaras D, Williams G J, Hau-Riege S, Timneanu N, Caleman C, Chapman H N, Boutet S, and Schlichting I (2015) Indications of radiation damage in ferredoxin microcrystals using high-intensity X-FEL beams. J. Synchrotron. Radiat. 22, 225238.

Oshima A, Tani K, Toloue M M, Hiroaki Y, Smock A, Inukai S, Cone A, Nicholson B J, Sosinsky G E, and Fujiyoshi Y (2011) Asymmetric configurations and $\mathrm{N}$-terminal rearrangements in connexin26 gap junction channels. J. Mol. Biol. 405, 724-735.

Paulino C, Wohlert D, Kapotova E, Yildiz O, and Kuhlbrandt W (2014) Structure and transport mechanism of the sodium/proton antiporter MjNhaP1. Elife 3, e03583.

Pope C R and Unger V M (2012) Electron crystallography-the waking beauty of structural biology. Curr. Opin. Struct. Biol. 22, 514-519.

Purdy J G, Flanagan J M, Ropson I J, Rennoll-Bankert K E, and Craven R C (2008) Critical role of conserved hydrophobic residues within the major homology region in mature retroviral capsid assembly. J. Virol 82, 5951-5961.

Raunser S and Walz T (2009) Electron crystallography as a technique to study the structure on membrane proteins in a lipidic environment. Annu. Rev. Biophys. 38, 89-105.

Rodriguez J A, Ivanova M I, Sawaya M R, Cascio D, Reyes F E, Shi D, Sangwan S, Guenther E L, Johnson L M, Zhang M, Jiang L, Arbing M A, Nannenga B L, Hattne J, Whitelegge J, Brewster A S, Messerschmidt M, Boutet S, Sauter N K, Gonen T, and Eisenberg D S (2015) Structure of the toxic core of alpha-synuclein from invisible crystals. Nature 525, 486-490.

Ruprecht J J, Mielke T, Vogel R, Villa C, and Schertler G F (2004) Electron crystallography reveals the structure of metarhodopsin I. EMBO J. 23, 3609-3620.

Schenk A D, Castano-Diez D, Gipson B, Arheit M, Zeng X, and Stahlberg $H$ (2010) 3D reconstruction from 2D crystal image and diffraction data. Methods. Enzymol. 482, 101-129.

Scherer S, Arheit M, Kowal J, Zeng X, and Stahlberg H (2014) Single particle $3 \mathrm{D}$ reconstruction for $2 \mathrm{D}$ crystal images of membrane proteins. $J$. Struct. Biol. 185, 267-277.

Shi D, Nannenga B L, ladanza M G, and Gonen T (2013) Threedimensional electron crystallography of protein microcrystals. Elife $\mathbf{2}$, e01345.

Wisedchaisri G and Gonen T (2011) Fragment-based phase extension for three-dimensional structure determination of membrane proteins by 
electron crystallography. Structure 19, 976-987.

Wisedchaisri G, Reichow S L, and Gonen T (2011) Advances in structural and functional analysis of membrane proteins by electron crystallography. Structure 19, 1381-1393.
Yonekura K, Kato K, Ogasawara M, Tomita M, and Toyoshima C (2015) Electron crystallography of ultrathin 3D protein crystals: atomic model with charges. Proc. Natl. Acad. Sci. U S A 112, 3368-3373. 